\title{
A NOTE ON THE BAUER-KORNAI INVESTMENT CYCLE THEORY
}

\author{
Heng-fu Zou
}

\begin{abstract}
This short paper has fornulated the Bauer-Komai investment cycle theory in a dynamic system of shortage and the investment rave: when the actual investment rate is higher (lower) than the normal one, the shortage intensity tends to intensify (decrease); when the shortage intensity is above (below) the nonn, social planners react to lower (raise) the investment rate. This approach of adjustment by norm has boen widely applied to empirical work on investment fluctuations in socialist countries, though the rationality of the investment cycles has been ignored by many. Here it has been shown that this cycle model can be explicitly derived from the rational choice of social planners. JEL Classification numbers: E22, E32, P26, P24.
\end{abstract}

\section{INTRODUCTION}

The economic explanation of investment cycles has been offered by Bauer (1978) and Kornai (1980, 1986). Many empirical studies have followed the same reasoning, e.g., Grosfeld (1987) and Roland (1987). The main idea of the Bauer-Kornal approach is the following: social planners adjust the investment rate according to the shortage intensity in the economy; when shortage is below or around the normal state, social planners approve and initiate large numbers of projects. The high investment rate will soon overheat the economy, and shortage intensity will exceed the normal level and become intolerable. Social planners will react to halt all new investment and cut or stop quite a few existing investment projects. After this slowdown process lasts for a while, shortage intensity is reduced and more slack is revealed. There comes a new wave of optimism, and a new cycle starts again.

In this paper, I intend to deal with the following questions: If social planners can perceive the effects of their action, which is possible from repeated practices, why do they not follow a smoother pattern of invesment? Is the cycle itself an optimal choice of the social planners? I answer these questions in two sections. In Section $\Pi$, I will focus on the dynamic relation between the shortage intensity and the investment rate. With some over-simplification, but without sacrifice of the essence, I reformulate the Bauer-Kornai cycle theory in the familiar Volterra-Lotka equations of cycles. I begin Section III by defining social planners' preference. It will be justified that social planners derive positive utility from high investment rate and negative utility or disutility from high shortage intensity in the economy. If social planners' preference is defined in a special way, investment cycles can be shown to be the rational choice of social planners.

Direct all correspondence to: $\quad$ Heng-fu Zou, Public Economics Division, World Bank, Washington, D. C. 20433. 


\section{THE BAUER-KORNAI INVESTMENT CYCLE THEORY}

I first present a stylized description of the Bauer-Kornai investment cycle theory.

In the upswing of investment cycle, the economy is in a state of run-up and rush. An increasing number of investment projects is approved, and many new investments are initiated, and the existing projects are accelerated and expanded. This process continues until the economy hits the "tolerance limits":

1. high rate of investment leads to serious shortage of consumption goods that various forms of protest by consumers take place;

2. large number of investment projects compete with each other in investment inputs, and shortage of certain materials, late deliveries, bottlenecks and many other shortage phenomena become intolerable;

3. continued high rate of investment brings about large foreign trade deficit and debt accumulation.

All these send alarm signals to social planners, and they react to suddenly halt all new investment projects and cut or stop many existing projects. The economy enters into a state of slowdown and the investment rate is often substantially reduced.

After some time, the shortage intensity is reduced considerably; producers find a relatively small volume of unfilled orders, consumers are more often in a short queue. So "there is too much slack" in the economy, "more could be squeezed out of investment sphere. This increasingly optimistic spirit suddenly becomes a strong determination and a new impetus is given to investment activity. The cycle starts again" (Kornai, 1980, pp. 213-14).

It seems to me that the essential parts of this cycle theory can be summarized in two dynamic equations. The first equation governs the dynamics of the shortage intensity: if the investment rate exceeds some normal rate, shortage tends to intensify; if the investment rate is below the normal level, the shortage intensity mitigates. The second equation describes the behavior of social planners: facing high and intolerable shortage phenomena, social planners lower the investment rate; and when the shortage intensity is well below certain critical or normal level, they raise the investment rate. Let me denote the investment rate as $k$ and the shortage intensity as $z$. Also denote the normal investment rate as $k^{*}$ and the normal shortage intensity as $z^{*}$. Rates $k^{*}$ and $z^{*}$ are assumed to be constant here. The concept of normality has been well studied by Kornai $(1971,1980,1982)$ and plays a central role in the understanding of the centrally planned economies. For elaboration, I refer readers to Kornai's original works.

Mathematically we write the change in the shortage intensity as a positive and linear function of the difference between the actual investment rate and the normal investment rate:

$$
\frac{\dot{z}}{z}=A\left(k-k^{*}\right) \quad A>0
$$

The equation regarding social Planners' behavior takes the following form:

$$
\frac{\dot{k}}{k}=B\left(z^{*}-z\right) \quad B>0
$$




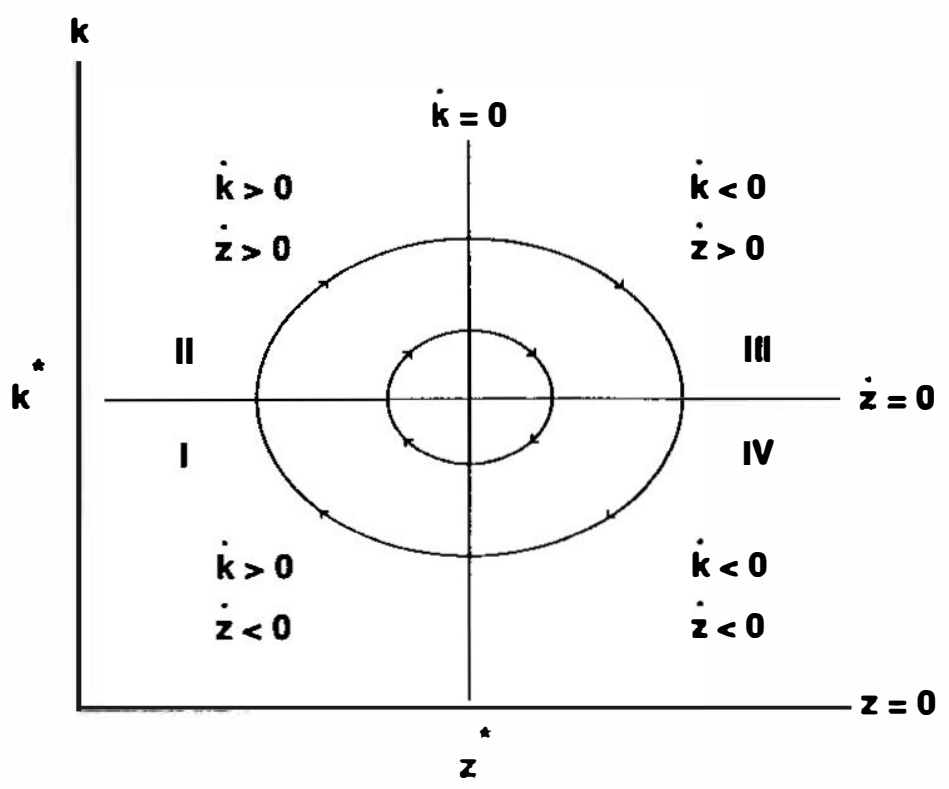

Figure 1.

For simplicity, I set constants $A$ and $B$ to unity. Equations (1) and (2) are just the Volterra-Lotka model in terms of the shortage intensity and the investment rate, and their application can be found in the predator-prey model in biology and the Goodwin-cycle in economics (Goodwin, 1967). Following the discussion in Hirsch and Smale (1974), I depict the phase diagram in figure 1.

The equilibrium points are given by $\left(z^{*}, k^{*}\right)$ and $(0,0)$. The interesting equilibrium is the normal levels of shortage and investment. It is proved that $\left(z^{*}, k^{*}\right)$ is a stable equilibrium, and there exists no limit cycle in the model, and every trajectory of these two equations is a closed orbit except the two equilibria, see Hirsh and Smale (1974). Therefore, for any given initial shortage intensity and investment rate other than $\left(z^{*}, k^{*}\right)$, shortage and investment will oscillate cyclically.

In region $\mathrm{I}$, as $z$ is less than $z^{*}$, and $k$ less than $k^{*}$, the investment rate goes up and shortage is expected to go down. This region is more or less like the period of run-up called by Tamas Bauer. Region II is Bauer's rush period, where the investment rate exceeds the normal rate and the shortage level increases; sooner or later, the tolerance limit will be hit and the social planners begin to "pull the brake." So in region III, investment rate is reduced and shortage continues to rise for a while. This slowdown process is typically manifested in region IV where both the investment rate and the shortage intensity begin to decrease.

Now the questions. Does equation (2) really reflect the optimal choice of the social planners? Why should social planners stick to the cyclical path instead of some smooth one? We take up these questions in the next section. 


\section{THE RATIONAL INVESTMENT CYCLE}

To derive social planners' optimal decision rule from explicit rational choice, we first define social planners' objective function. Social planners are a large group of people who are in charge of all economic organizations and management in a socialist economy. With both political power and economic resources in their control, "they pursue their own individual and group interests, including the interests of the particular specialized agency to which they belong. Power creates an irresistible temptation to make use of it" (Kornai, 1986). It is a common phenomenon that social planners in all socialist economies have placed the highest priority on capital accumulation, and "investment hunger" and "expansion -drive" are the most important characteristics of socialist economic growth. According to Kornai (1981, $1986,1988)$, it is in their own interests for social planners to accelerate investment and capital accumulation, because the expansion of the organization or firms is a way for social planners to identify themselves with their own jobs; "a larger organization brings more prestige, and also more power" (Kornai, 1981).

Of course, social planners do care about the shortage intensity caused by the high rate of investment. Chronic and excessive shortage often brings about consumers' dissatisfaction with social planners' manipulation of power, and the overextended investment policy may lead to complaints, wild strikes or demonstration, or open revolt.

Taking these two aspects into account, social planners enjoy positive utility from the invesiment rate and derive disutility from shortage if its intensity is very high. Using the notations in the last section, I write their instantaneous utility function as $u(k)-v(z)$. I further assume that functions $u(k)$ and $v(z)$ are twice continuously differentiable, with the property $u^{\prime}(k) \geq 0$, and $v^{\prime \prime}(z)>0$. As for the first order derivative of function $v(z)$, it is reasonable to assume that $v^{\prime}(z)>0$ for large value of the shortage intensity; if $z$ is below certain level, $v^{\prime}(z)$ may well be negative. Since $v^{\prime}(z)$ is continuous by assumption, there exists at least one value $z^{*}$ such that:

$$
v^{\prime}\left(z^{*}\right)=0
$$

For $v^{\prime \prime}(z)$ is strictly larger than zero for all $z, z^{*}$ satisfying (3) is unique.

Social planners maximize their utility over a finite horizon $[0, T]$ :

$$
\int_{0}^{T}[u(k)-v(z)] d t
$$

subject to the dynamic equation (2) in the last section:

$$
\frac{\dot{z}}{z}=\left(k-k^{*}\right)
$$

where $k$ is the control variable and $z$ is the state variable. The Hamiltonian function is:

$$
H(k, z, \lambda)=u(k)-v(z)+\lambda_{z}\left(k-k^{*}\right)
$$

The first-order conditions for maximization are: 


$$
\begin{aligned}
-\frac{u^{\prime}(k)}{z} & =\lambda \\
-v^{\prime}(z)+\lambda\left(k-k^{*}\right) & =-\lambda \\
z\left(k-k^{*}\right) & =\dot{z}
\end{aligned}
$$

where $\lambda$ is the costate variable. At time $T$, the boundary condition requires that $\lambda(T)=0$.

Now I will focus on the dynamics of equations (7), (8) and (9). Substituting $\lambda$ into (8), and manipulating some algebra, I obtain

$$
\begin{aligned}
& \dot{k}=-\frac{v^{\prime}(z) z}{u^{\prime \prime}(k)} \\
& \dot{z}=z\left(k-k^{*}\right)
\end{aligned}
$$

To get an exact Volterra-Lotka cycle of investment. I assume that social planners' utility function takes the following form:

$$
u(k)-v(z)=k \log k-z+z^{*} \log z .
$$

Also if the actual shortage is higher than the normal one, the marginal utility of shortage is negative; if the actual shortage is lower than the normal, the marginal utility of shortage is positive. Now the social planners' objective function is to maximize:

$$
W=\int_{0}^{T}\left[k \log k-z+z^{\bullet} \log z\right] d t
$$

subject to

$$
i=z\left(k-k^{*}\right)
$$

I will first show that social planners never take a smooth pattern of shortage and investment as their optimal choice in this case. If social planners set the investment rate at $k_{1}>k^{*}$ after some time $t_{1}$, then

$$
z(t)=e^{\left(k_{1}-\kappa^{*}\right) t}
$$

The integral (13) is equal to

$$
\begin{aligned}
W= & k_{1} \log k\left(T-t_{1}\right)-\frac{e^{\left(k_{1}-k^{*}\right) T}-e^{\left(k_{1}-k^{*}\right) t_{1}}}{\left(k_{1}-k^{*}\right)} \\
& +z^{*}\left(k_{1}-k^{*}\right)\left(T^{2}-t_{1}^{2}\right)+\text { some constant. }
\end{aligned}
$$


This will be a large negative number for large $T$ because $\left(k_{1}-k^{*}\right)$ is positive and the second term on the right hand side of (14) dominates all other terms.

Similarly, if social planners choose an investment rate $k_{1}$ less then $k^{*}$, the third term on the right hand side will become very negative and the second term approaches zero for a large value of $T$. Also note that the third term will dominate the first term as square of $T$ is greater than $T$ when $T$ is large. Therefore, $W$ goes negative for large $T$.

To find the optimal adjustment function for social planners, we let $u(k)=k \log k$, and $v(z)=z-z^{*} \log z$ in (9) and (10). The optimal conditions for this case upon substitution are:

$$
\dot{k}=-\frac{\left(1-z^{*} / z\right) z}{1 / k}
$$

and

$$
\dot{z}=\left(k-k^{*}\right) z
$$

Namely:

$$
\begin{aligned}
& \frac{\dot{k}}{k}=\left(z^{*}-z\right) \\
& \frac{\dot{z}}{z}=\left(k-k^{*}\right)
\end{aligned}
$$

which are exactly the Volterra-Lotka equations discussed in Section II. If the initial shortage intensity and investment rate are different from the equilibrium state $\left(z^{*}, k^{*}\right)$, the economy will oscillate throughout the time. In particular, the cycle is proved to be the rational choice of social planners.

\section{CONCLUSION}

In this short note, I have formulated the Bauer-Komai investment cycle theory in a dynamic system of shortage and the investment rate: when the actual investment rate is higher (lower) than the normal one, the shortage intensity tends to intensify (decrease); when the shortage intensity is above (below) the normal, social planners react to lower (raise) the investment rate. This approach of adjustment by norm has been widely applied to empirical work on investment fluctuations in socialist countries, though the rationality of the investment cycles has been ignored by many. Here, relying on some special example, I have shown that this cycle model can be explicitly derived from the optimal choice of social planners. In this limited sense we can say that investment cycles are chosen by social planners to maximize their utility. 


\section{ACKNOWLEDGMENTS}

I thank Richard Caves, Janos Kornai, Dwight Perkins, and Jeffrey Sachs for their help in writing this paper. Any remaining errors are mine. Responsibility for the contents of this paper is solely mine and not that of the World Bank.

\section{REFERENCES}

Bauer, T. 1978. Investment cycles in planned economies. Acta Oeconomica, 243-60.

Goodwin, R. 1967. A growth cycle. In C. H. Feinstein, ed., Socialism, capitalism and economic growth: Essays presented to Maurice Dobb. Cambridge: Cambridge University Press.

Grosfeld, I. 1986. Endogenous planners and the investment cycle in the centrally planned economies, Comparative Economic Studies (pp. 42-53). (Spring).

. 1987. Modelling planners' investment behavior: Poland, 1956-1981. Journal of Comparative Economics, 11, 180-191.

Hirsh, M., and S. Smale. 1974. Differential equations, dynamic system, and linear algebra. Academic Press.

Kornai, J. 1971. Anti-equilibrium. Amsterdam: North-Holland.

- 1980. Economics of shortage. Amsterdam: North-Holland.

1981. Some properties of the eastem European growth pattem, World Development, 9.

1982. Growth, shortage, and efficiency. Berkeley: University of California Press.

. 1986. The Hungarian reform process: visions, hopes, and reality. Journal of Economic Literatures, 26, 1687-1743.

Roland, G. 1987. Investment growth fluctuations in the Soviet Union: An econometric analysis. Journal of Comparative Economics, 11, 192-206.

Zou, Heng-fu. 1991. Socialist economic growth and political investment cycles. European Journal of Political Economy, 7, 141-157. 